\title{
Quantum-chemical modeling of structure and properties of nitrogen derivatives of phloroglucinol
}

\author{
C Dmitry S. Gusarov, ${ }^{2+}$ Mikhail A. Ryabov, ${ }^{1}$ Thi Ngok Anh Vu, ${ }^{1}$ and Olga V. Kovalchukova ${ }^{1,2} *$ \\ ${ }^{1}$ Depastment of General Chemistry. Peoples' Friendship University of Russia \\ (PFUR University). Miklukho-Maklaya St., 6. Moscow, 117198. Russia. \\ ${ }^{2}$ Department of Organic Chemistry. A.N. Kosygin Russian State University (Technology. Design. Art). \\ Sadovnicheskaya St., 33. P.1.Moscow, 115035.Russia.E-mail: gusarovbusyman@gmail.com
}

\begin{abstract}
*Supervising author; ${ }^{+}$Corresponding author Keywords: azo-derivatives, phloroglucinol, electronic absorption spectra, IR spectra, UV spectra, quantum-chemical modeling.
\end{abstract}

\begin{abstract}
The DFT/B3LYP quantum-chemical method has been used to simulate the structure of 2-((2hydroxyphenyl) diazonyl) benzene-1,3,5-triol $\left(\mathrm{L}^{1}\right)$ and 2-((2-hydroxy-4-nitrophenyl) diazonyl) benzene-1,3,5triol $\left(\mathrm{L}^{2}\right)$ molecules. The spatial and electronic structure of molecules in various tautomeric forms was determined. It was shown that the stability of these compounds is primarily due to the presence of strong intramolecular hydrogen bonds (IHB), which form six-membered cycles, and the isomerism of the molecule, which assume the formation of IHB. The structures where IHB form five-membered cycles, are less stable. In general, for the $\mathrm{L}^{1}$ and $\mathrm{L}^{2}$ molecules, azo-tautomers were found to be 4 and $3 \mathrm{~kJ} / \mathrm{mol}$ more stable than the hydrazo-tautomers, respectively. Such a small difference in energy of molecules for the gas phase did not allow us to conclude about the form of existence of molecules in solutions or in the crystalline state. To assess the possibility of transition between tautomers, we used the DFT method to calculate the transition states (TS) between the azo and hydrazo tautomers of the $\mathrm{L}^{1}$ and $\mathrm{L}^{2}$ molecules. The barrier of the transition from the azo form to the hydrazo form was found to be $14 \mathrm{~kJ} / \mathrm{mol}$ for the molecules $\mathrm{L}^{1}$ and $\mathrm{L}^{2}$, respectively. The interatomic distances, angles, charges on atoms, IR and electronic absorption spectra of tautomeric forms of $\mathrm{L}^{1}$ and $\mathrm{L}^{2}$ molecules were calculated. It has been established that the long-wave absorption band (LB) of the electronic absorption spectrum bathochromically shifts at transition from azo to hydrazo-tautomers by $41 \mathrm{~nm}$ for $\mathrm{L}^{1}$ and $40 \mathrm{~nm}$ for $\mathrm{L}^{2}$. The introduction of a nitro group also leads to a bathochromic shift of the LB by 22 $\mathrm{nm}$ at transition from azo-tautomer $\mathrm{L}^{1}$ to hydrazo- $\mathrm{L}^{1} \mathrm{~L}^{2}$ and by $21 \mathrm{~nm}$ at transition from azo- $\mathrm{L}^{2}$ to hydrazo- $\mathrm{L}^{2}$.
\end{abstract}

\section{References}

[1] S.B. Strashinova, O.V. Kovalchukova, E.P. Romashkina, O.V. Avramenko, and O.V. Volyansky. Quantum-chemical modeling of the metal chelate cycles of methylphloroglucine phenylazo derivatives. Butlerov Communications. 2013. Vol.33. No.1. P.78-82. ROI: jbc-02/13-33-1-78

[2] O.V. Kovalchukova, S.B. Strashnova, P.V. Strashnov, E.P. Romashkina, O.V. Volyanskiy, and K.I. Kobrakov. Spectral and quantum-chemical studies of tautomeric and ionic transformations of azo-dyes based upon methylfloroglucine. Butlerov Communications. 2011. Vol.24. No.1. P.90-94. ROI: jbc-02/11$24-1-90$

[3] A.D. Becke. Density-functional thermochemistry. III. The role of exact exchange. J. Chem. Phys. 1993. Vol.98. P.5648-5652.

[4] C. Lee, W. Yang, and R.G. Parr Development of the Colle-Salvetti correlation-energy formula into a functional of the electron density. Phys. Rev. 1988. B37. P.785-789.

[5] P.J. Stephens, F.J. Devlin, C.F. Chabalowski, M.J. Frisch. Ab initio calculation of vibrational absorption and circular dichroism spectra using density functional force fields. J. Phys. Chem. 1994. Vol.98. P.11623-11627.

[6] A. Schaefer, C. Huber, R. Ahlrichs. Fully optimized contracted Gaussian-basis sets of triple zeta valence quality for atoms Li to Kr. J. Chem. Phys. 1994. Vol.100. P.5829-5835.

[7] NBO 5.G. E.D. Glendening, J.K. Badenhoop, A.E. Reed, J.E. Carpenter, J.A. Bohmann, C.M. Morales, F. Weinhold. Theoretical Chemistry Institute, University of Wisconsin, Madison, WI. 2004. http://www.chem. wisc.edu/ nbo5

[8] Alex A. Granovsky, Firefly version 7.1.G, www http://classic.chem.msu.su/gran/firefly/index.html 